Association for Information Systems AIS Electronic Library (AISeL)

2018

\title{
Learning Scorecard Gamification: application of the MDA framework
}

Tiago Pedroso

ISCTE-Instituto Universitário de Lisboa, Tiago_Pedroso@iscte-iul.pt

Elsa Cardoso

ISCTE-IUL, INESC-ID, Elsa.Cardoso@iscte-iul.pt

Francisco Rações

ISCTE-IUL, Francisco_Barao@iscte-iul.pt

Artur Baptista

ISCTE-IUL, Artur_Teixeira@iscte-iul.pt

José Barateiro

LNEC, INESC-ID, jose.barateiro@lnec.pt

Follow this and additional works at: https://aisel.aisnet.org/capsi2018

\section{Recommended Citation}

Pedroso, Tiago; Cardoso, Elsa; Rações, Francisco; Baptista, Artur; and Barateiro, José, "Learning Scorecard Gamification: application of the MDA framework" (2018). 2018 Proceedings. 17.

https://aisel.aisnet.org/capsi2018/17 


\title{
Gamificação do Learning Scorecard: aplicação da framework MDA
}

\author{
Learning Scorecard Gamification: application of the MDA framework
}

\author{
Tiago Pedroso, ISCTE- Instituto Universitário de Lisboa (ISCTE-IUL), Portugal, \\ Tiago_Pedroso@iscte-iul.pt \\ Elsa Cardoso, ISCTE-IUL e INESC-ID, Portugal, Elsa.Cardoso@iscte-iul.pt \\ Francisco Rações, ISCTE-IUL, Portugal, Francisco_Barao@iscte-iul.pt \\ Artur Baptista, ISCTE-IUL, Portugal, Artur_Teixeira@iscte-iul.pt \\ José Barateiro, LNEC e INESC-ID, Portugal, jose.barateiro@lnec.pt
}

\begin{abstract}
Resumo
A aplicação de técnicas de gamificação no ensino superior é um desafio; em diferentes momentos facilmente se perde o foco e deixamos de conseguir explicar as ligações entre as motivações dos jogadores e os elementos que constituem o jogo. Este estudo focou-se na aplicação da framework MDA (Mechanics, Dynamics and Aesthetics) numa plataforma designada de Learning Scorecard (LS), utilizada por dezenas de alunos no ISCTE - Instituto Universitário de Lisboa. O LS é uma plataforma de Learning Analytics, que tem sido usada em Unidades Curriculares de Data Warehouse e Business Intelligence desde 2016. O LS possui duas visões independentes: a vista de aluno e a vista de docente. Neste trabalho apenas reportamos a aplicação dos diferentes passos da framework MDA no LS na vista de aluno. Esta vista procura melhorar a experiência de aprendizagem dos alunos conseguindo melhorar o seu compromisso e motivação através do uso da gamificação.
\end{abstract}

Palavras-chave: Gamificação; Learning Scorecard; Framework MDA

\begin{abstract}
The application of gamification techniques in higher education can be challenging. At times it is easy to loose focus and we can no longer explain the connections between players' motivation and the several elements of the game. This study focused on the application of the MDA framework (Mechanics, Dynamics and Aesthetics) to the platform Learning Scorecard (LS), currently used by dozens of students at ISCTE - Instituto Universitário de Lisboa. The LS is a platform for Learning Analytics that has been used since 2016, on courses of Data Warehouse and Business Intelligence. LS has two views: the student and teacher views. In this work we will report solely on the application of the MDA framework to the student view of LS. This view aims to improve the learning experience of students improving their engagement and motivation through the use of gamification.
\end{abstract}

Keywords: Gamification; Learning Scorecard; MDA Framework

\section{INTRODUÇÃo}

A gamificação é a utilização de elementos de game design aplicados em contextos diferentes aos jogos (Deterding, Dixon, Khaled, \& Nacke, 2011). A gamificação no ensino tem vindo a crescer 
consideravelmente, conforme é comprovado pela quantidade de trabalhos publicados nesta área (Dicheva, Dichev, Agre, \& Angelova, 2015), devido à necessidade de alterar o ensino para melhorar resultados. Segundo Hanus e Fox (2015) os alunos podem ser motivados a aprender de novas formas ou pela reformulação das aborrecidas formas de ensino. A gamificação é um novo modo de ensinar que pode alterar as práticas pedagógicas mais tradicionais numa perspetiva mais inovadora (Regina, Losso, \& Borges, 2015). Ainda antes de o termo gamificação ser falado o escritor, na área da edução, Marc Prensky defendia que as escolas deviam evoluir e passar a adaptar-se aos meios tecnológicos, porque as características dos alunos mudaram radicalmente. Ele afirma que os alunos de hoje já não são as pessoas para quem o sistema educacional foi projetado (Prensky, 2001). Lee e Hammer (2011) também defendem a aplicação da gamificação para alterar os métodos de educação mais tradicionais.

Os principais desafios da gamificação no ensino são o ceticismo dos reais benefícios desta técnica. A grande mudança que a implementação de mecanismos de gamificação comporta é outro grande problema. A mudança implica custos (tempo e dinheiro) e uma mente aberta para aceitar as mudanças. Por outro lado, os fatores positivos demonstram serem capazes de melhorar os processos de ensino que não têm sido capazes de ir de encontro com as exigências dos novos alunos conforme já apresentado (Furdu, Tomozei, \& Köse, 2017; Sánchez-Mena \& Martí-Parreño, 2017).

O objetivo deste estudo é apresentar de forma crítica os passos necessários para a construção de um sistema com gamificação, no âmbito do Learning Scorecard, uma plataforma de Learning Analytics desenvolvida num contexto universitário, cujo foco é melhorar o compromisso e a motivação dos alunos com vista a aumentar a sua experiência de aprendizagem numa unidade curricular (UC).

O documento encontra-se organizado da seguinte forma. A secção 2 descreve os conceitos e as técnicas a aplicar na construção do sistema com elementos de gamificação. A secção 3 demonstra a aplicação dos conceitos e da framework MDA num caso real, i.e., na plataforma Learning Scorecard. Na secção 4 é feita a análise dos resultados da experiência realizada. Finalmente, na secção 5 são apresentadas as conclusões, as dificuldades encontradas no estudo e as melhorias propostas como trabalho futuro.

\section{Game Design}

Game design é o processo de criação de um jogo através de elementos e técnicas (Németh, 2015). Os elementos e as técnicas de game design são usados para motivar e encorajar os jogadores para que eles realizem com prazer e compromisso as suas tarefas. Mas em certas circunstancias, apenas a alegria de jogar e/ou a possibilidade de ganhar criam por si só um estimulo competitivo entre os 
jogadores (Dicheva et al., 2015). Assim é possível demostrar a capacidade motivacional destes elementos e técnicas de gamificação.

Um termo muito usado na gamificação é o de elementos de gamificação ou elementos de game design, mas o termo é bastante vasto. A consciencialização do termo elementos de game design é uma barreira. Os autores geralmente não diferenciam as funções de cada elemento e nem os distinguem (Monterrat, Lavoué, \& George, 2017). Ainda assim quando o fazem "não existe uma classificação comum dos elementos de game design, a classificação não é clara para estes elementos" (Dicheva et al., 2015). Deparando com problema de falta de concordância surgem algumas taxonomias, entre elas destaca-se a framework MDA (Mechanics, Dynamics and Aesthetics) que é vista como uma taxonomia popular entre os profissionais da indústria da gamificação.

A framework MDA proposta por Hunicke, LeBlanc e Zubek (2004) é uma análise pós-morte dos elementos do jogo, que permite utilizar os sistemas de pensamento para descrever a interação desses elementos e aplicá-los fora do conceito do jogo (ver Figura 1). O seu nome deve-se a ser composto por três categorias chamadas de Mechanics (mecânicas), Dynamics (dinâmicas) e Aesthetics (estéticas). As mecânicas formam os componentes funcionais do jogo com a capacidade de orientar as ações dos jogadores. As dinâmicas são as interações do jogador com as mecânicas incorporadas nos sistemas determinando o que cada jogador faz. Por fim, as estéticas são as emoções que o jogo transmite para o jogador durante o seu uso. A estética pode ser entendida como a composição das mecânicas e das dinâmicas à medida que os jogadores interagem (Zichermann \& Cunningham, 2011).

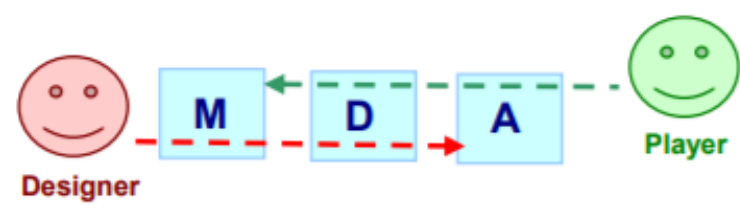

Figura 1 - Perspetivas do MDA (Hunicke et al., 2004)

\section{MDA NO LEARNING SCORECARD}

A plataforma Learning Scorecard (LS) permite aos alunos do Ensino Superior monitorizarem a sua evolução de aprendizagem (Cardoso et al., 2017; Cardoso, Costa, \& Santos, 2016). Esta plataforma permite gerar dados que, ao longo do semestre letivo, apoiam os professores a supervisionar de forma contínua as suas turmas. O LS utiliza técnicas de gamificação para procurar aumentar o compromisso/envolvimento dos alunos com as unidades curriculares. Também procura usar as melhores práticas de Business Intelligence para oferecer aos alunos e aos professores um ambiente analítico para que seja possível monitorizarem o seu desempenho. 
O LS está em curso por quatro semestres consecutivos, desde o ano letivo 2016-17, no ISCTEInstituto Universitário de Lisboa (ISCTE-IUL) nas Unidades Curriculares de Sistemas Informáticos de Apoio à Decisão (SIAD) I e II, onde são lecionadas as temáticas de Data Warehouse e Business Intelligence. Em cada uma das interações surgiram modificações contando a plataforma já com quatro versões, sendo que duas delas foram desenvolvidas no âmbito desta investigação.

A plataforma apresenta duas vistas, a do aluno e a do docente. A vista de aluno foca-se na gestão do tempo, na monitorização e conta com as técnicas de gamificação para melhorar a experiência de aprendizagem individual dos alunos. A vista de docente tem o objetivo de aumentar a comunicação dos docentes com os alunos e personalizar a experiência de aprendizagem dos alunos.

A gamificação presente nas versões 3 e 4 da plataforma LS seguiu os seis passos apresentados no Livro "For the win" para a construção do game design (Werbach \& Hunter 2012). Os passos consistem em Definir os objetivos (passo 1) cujo o objetivo principal da utilização das técnicas de gamificação no LS passa por aperfeiçoar a experiência de aprendizagem dos alunos com a melhoria do comprometimento e/ou a motivação.

Delinear comportamentos pretendidos (passo 2), neste passo o comportamento esperado é de que os alunos acompanhem as matérias lecionadas ao longo do semestre para que consigam realizar um estudo equilibrado de forma divertida e, por conseguinte, uma melhoria das médias das notas na Unidade Curricular.

Descrever os jogadores (passo 3), como anteriormente referido os utilizadores da plataforma são jovens adultos que frequentam as Unidades Curriculares de SIAD. O facto de os estudantes serem jovens poderá ajudar na motivação e aceitação do LS.

Desenhar loops de atividades (passo 4), neste ponto foi definido que os alunos terão de completar tarefas e missões e consequentemente ganharam pontos de experiência por os terem realizado como um mecanismo de feedback. Este feedback terá de ser dado o mais cedo possível, não podendo ser em tempo real devido ao motivo de muitos destes desafios terem de ser corrigidos ou aprovados por um docente. Com os pontos ganhos (feedback) e possíveis subidas de ranks estamos a motivar os jogadores a agir de novo, completando desta forma o ciclo de engagement proposto por Werbach e Hunter (2012), que fará com que os jogadores estejam comprometidos e motivados.

Não esquecer a diversão (passo 5) é um ponto muito importante quando se pretende construir um sistema gamificado que é muitas vezes descurado. Para não esquecer a diversão será utilizada a framework MDA. 
Utilizar ferramentas apropriadas (passo 6) é o último ponto e para este caso seguimos a regra principal da gamificação que diz que o sistema deve ser "iterado, melhorado, testado, iterado, melhorado, testado, ...". Devemos continuamente procurar melhorar os nossos sistemas utilizando as ferramentas disponíveis.

Noutro sentido foi utilizada a framework MDA como taxonomia dos elementos do game design para facilitar a compreensão das perspetivas dos criadores do jogo e dos jogadores. Assim com a aplicação do MDA torna-se possível distinguir os diferentes elementos dos jogos como as regras, o sistema e a diversão. Seguidamente serão descritos os diferentes passos da aplicação do MDA na plataforma Learning Scorecard.

\subsection{Mecânicas no LS}

As mecânicas escolhidas para orientar os jogadores ao longo do jogo foram os XPs (experience points) que permitem representar numericamente a progressão dos jogadores no jogo. Os pontos são ganhos na plataforma com a conclusão de diferentes objetivos como missões (Quests), troféus (Trophies) e medalhas (Badges). A utilização dos Ranks ou níveis na plataforma LS permitiu definir as diferentes etapas na progressão dos jogadores.

Os Ranks seguem a escala de avaliação de A a F, mas com um nome motivador para cada escala (A - Legendary, B - Master, C - Expert, D - Skilled, E - Rookie e F - Newbie).

As Quests são desafios pré-definidos com objetivos e recompensas. Na plataforma LS as Quests são o principal mecanismo para os jogadores ganharem XPs. Os tipos de Quests disponíveis no Learning Scorecard são: Quizzes (testes de escolha múltipla), Practical Assignments (tutorias), Exercises (exercícios escritos), Class Attendance (assiduidade nas aulas) e Forum (participação no fórum). Os alunos terão que validar e classificar a dificuldade de determinadas Quests (Quiz, Exercise e Practical Assignment) definidas pelos docentes para poderem ganhar os XPs associados. Associado a esta mecânica surgiu a necessidade de criar os Last Chances; este mecanismo permite dar um bónus aos jogadores de forma a que possam validar e classificar de novo as Quests que tinham realizado, mas não validado. As Last Chances podem implicar uma penalização, definida pelo docente, nos XPs ganhos por não terem validado na altura devida.

Também associadas às Quests existem os eventos que são guias do jogo que não premeiam os jogadores com XPs ao serem completados. Os jogadores caso falhem algum evento obrigatório da UC passam para um estado de Game Over no jogo.

As Guilds são o nome chamado aos grupos de trabalho das UC. Outro mecanismo também criado foi o conceito de Alliance (aliança) que representa o turno em que o aluno assiste às aulas. 
Na plataforma LS utilizou-se uma das mecânicas mais utilizadas as Leaderboards, mas com uma particularidade de serem leaderboards multidimensionais com as seguintes 5 dimensões:

- Leaderboard All, são ordenados os jogadores por ordem decrescente de todos os XPs acumulados na UC (ver Figura 2);

- Leaderboard Quizzes, são ordenados os jogadores por ordem decrescente dos XPs ganhos em quests do tipo quizzes na UC;

- Leaderboard Exercises, são ordenados os jogadores por ordem decrescente dos XPs ganhos em quests do tipo exercises na UC;

- Leaderboard Guilds, são ordenados os grupos de alunos ou Guilds por ordem decrescente da média de XPs acumulados pelos elementos do grupo na UC; e

- Leaderboard Combined, são ordenados os jogadores por ordem crescente pela soma das posições obtidas das leaderboads all, quizzes e exercises.
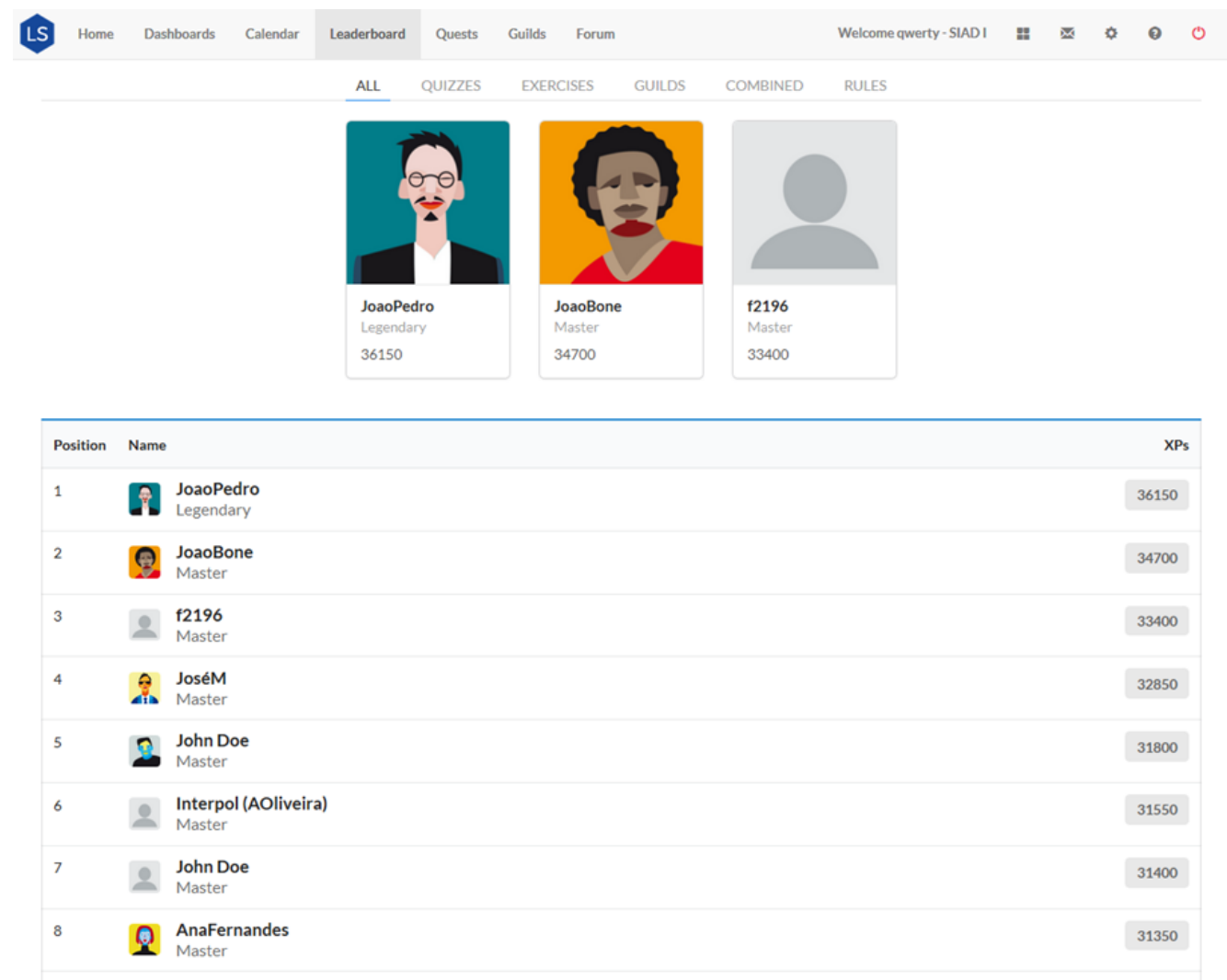

Figura 2 - Leaderboard All do LS versão 3

Interligado com as leaderboards surge uma nova mecânica, trophies (troféus), que premeia os jogadores que se encontrem na primeira posição das leaderboards all (troféu Best Score Player), guild (troféu Best Guild) e combined (troféu Best Triathlon Player) com 1000 XPs. O troféu corresponde a uma quantia avultada de XPs. 
Aos jogadores deu-se a possibilidade de personalização do seu perfil com a introdução de Avatars. Criou-se um sistema onde os jogadores à medida que sobem de ranks vão desbloqueando novos Avatars, sempre com Avatars masculinos e femininos (ver Figura 3).

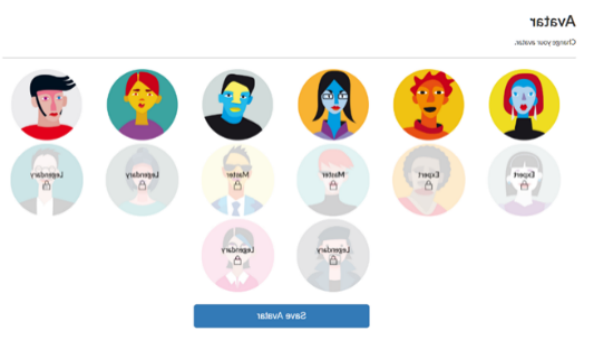

Figura 3 - Avatares disponíveis no LS versão 3

Também se disponibilizou aos jogadores um Dashboard de gaming para os alunos poderem ver o seu percurso e tomarem decisões ao longo da sua experiência no jogo (ver Figura 4).

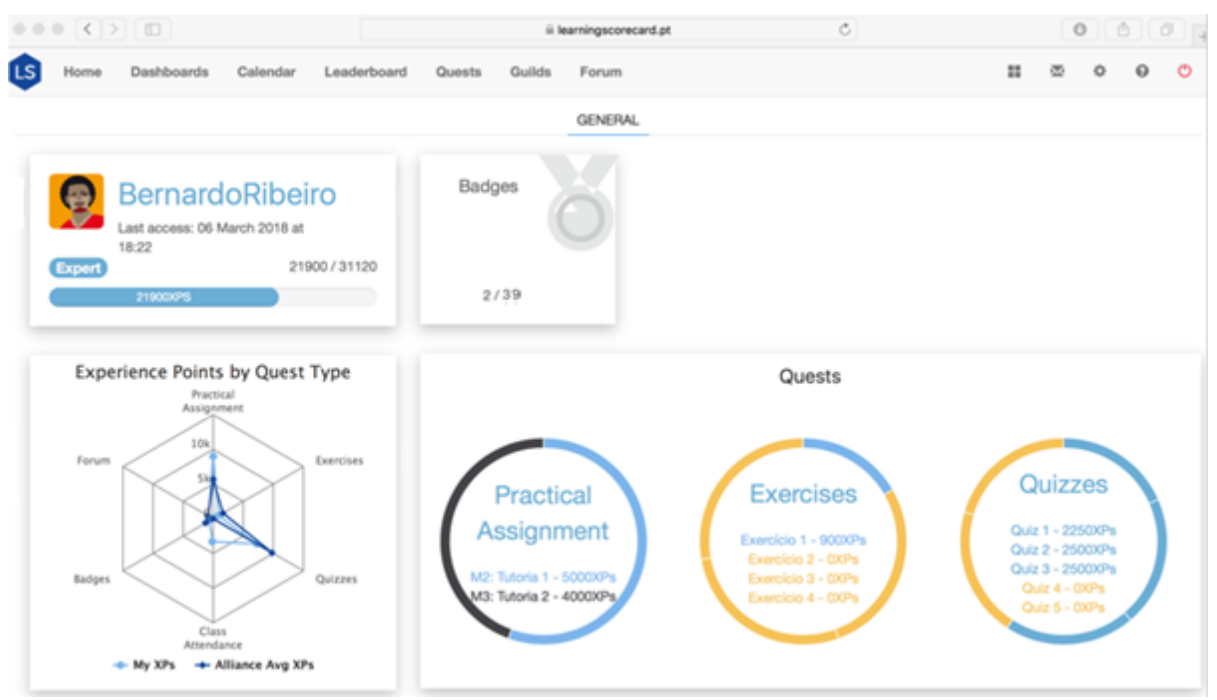

Figura 4 - Dashboard do aluno no LS versão 3

Outra mecânica inserida no LS são os badges (medalhas), este é outro dos mecanismos que permite guiar os alunos pelo jogo e é outro sistema de obtenção de XPs. Existem na plataforma 39 badges que se dividem em quatro modalidades os individuais, os de Guild, os do fórum e os de realização do questionário final. Estes badges ainda se dividem em diferentes materiais como o bronze, a prata, o ouro e a platina à medida que os desafios são mais difíceis de serem realizados.

\subsection{Dinâmicas no LS}

Na plataforma LS procurou-se explorar diferentes dinâmicas com maior foco na cooperação e na competitividade. Os jogadores do LS são jovens estudantes o que permite que as dinâmicas de competitividade e cooperação possam ser bem exploradas. 
A cooperação foi estimulada com a utilização das mecânicas de Guilds e Alianças onde se procura um foco na entreajuda. Para complementar o espírito de equipa adicionamos às Leaderboards, os Badges e os Trophies orientados às Guilds. Outro ponto que permitiu a ajuda entre todos os alunos foi o fórum, que facilitou a partilha de conhecimento entre os alunos, bem como a comunicação com os professores e o esclarecimento de dúvidas.

A construção de uma narrativa para guiar os jogadores ao longo da experiência gamificada insere na plataforma LS as dinâmicas de continuidade e conclusão do jogo. Estas duas dinâmicas foram exploradas essencialmente com a utilização dos eventos e quests. Estas duas técnicas interligadas com os ranks e os XPs permitem dar um feedback constante promovendo o comprometimento dos alunos com a plataforma. A quantidade de quests e badges disponíveis com o decorrer da UC possibilitou também melhorar a dinâmica de escolha e consequência no LS, os alunos podem tomar decisões como escolher o seu percurso ao longo do jogo. Nestes sistemas gamificados é muito importante garantir a possibilidade de falhar para não levar à perda de motivação e comprometimento dos alunos. A enorme quantidade de desafios disponíveis e a introdução dos Last Chances possibilitou dar aos jogadores a possibilidade de falhar ou errar.

Por fim, mas não menos importante procuramos incentivar a competição saudável entre os jogadores. Para tal foi importante a utilização de grande parte das mecânicas inseridas na plataforma. As leaderboards são o principal mecanismo de comparação entre os jogadores. Por isso, a criação de cinco leaderboards possibilitou incitar a competição, onde são exploradas diferentes Quests como os Quizzes e os Exercises. A atribuição de troféus ao melhor jogador e à melhor Guild teve o mesmo objetivo de proporcionar a competição e de premiar os jogadores pelo esforço realizado ao longo da experiência. Procurou-se com a competitividade entre as Guilds fazer com que os elementos se motivassem mutuamente. Os XPs e os Ranks foram os mecanismos usados para a comparação nas leaderboards, mas é importante não esquecer que os Avatars como vão sendo desbloqueados com a subida de ranks por parte dos jogadores permitem que estes "espicacem" os outros jogadores de rank inferior.

Com as principais dinâmicas apresentadas acima será possível criar um sistema capaz de cobrir e motivar todos os tipos de jogadores.

\subsection{Estéticas do LS}

A estética é o último ponto da framework MDA, neste passo o desafio passou por desencadear respostas emocionais aos jogadores com a criação das dinâmicas exploradas na plataforma LS. A plataforma é capaz de desencadear diferentes sensações dependendo de aluno para aluno. A adição da gamificação no LS procurou criar um grupo de alunos ativos e que cooperassem entre si para 
melhorar o seu conhecimento. A gamificação também procurou chegar aos alunos através de desafios e de uma nova experiência de ensino.

A melhoria do aspecto visual da plataforma permitiu melhorar os diferentes estímulos aos jogadores. O desenho das interfaces gráficas mereceu um cuidado especial no desenvolvimento do LS, por forma a melhorar a experiência de utilização da plataforma. Por exemplo, o Fórum na plataforma LS foi desenvolvido com xenForo, um sotfware proprietário de fóruns, o que permitiu a disponibilização rápida de um conjunto de funcionalidades de engagement social, alertas, personalização do perfil, estatísticas de atividade, valorizadas pelos alunos.

\section{Análise de RESUltados}

Os resultados analisados nesta secção correspondem aos dados obtidos a partir da utilização dos alunos com a plataforma e das suas respostas dadas no questionário final da UC da versão 3 do LS. A versão 3 foi utilizada numa UC do $1^{\circ}$ semestre do ano letivo 2017-2018, entre 24 setembro 2017 e 29 janeiro 2018, com 132 alunos inscritos. A UC foi lecionada simultaneamente a quatro cursos distintos, dois de mestrado e dois de licenciatura. Os dados de utilização da atual versão 4 ainda não podem ser analisados pois a experiência só encerra no início de julho 2018 .

$\mathrm{Na}$ versão 3 existiu um grande interesse dos alunos para com a plataforma onde $93 \%$ dos alunos (123 de 132) participaram nesta experiência de aprendizagem. A partir dos questionários cerca de 96\% dos inscritos na plataforma utilizou-a até ao final do semestre. Um dos motivos que permitiu estes altos valores no comprometimento advém do facto da participação do LS contribuir para a nota final da UC conforme é realçado por alguns alunos nos questionários, "é mais uma plataforma, obrigatória, que condiciona a nota”. Noutro sentido, a razão que levou os (poucos) alunos a não utilizarem a plataforma até ao fim do semestre foi a falta de tempo.

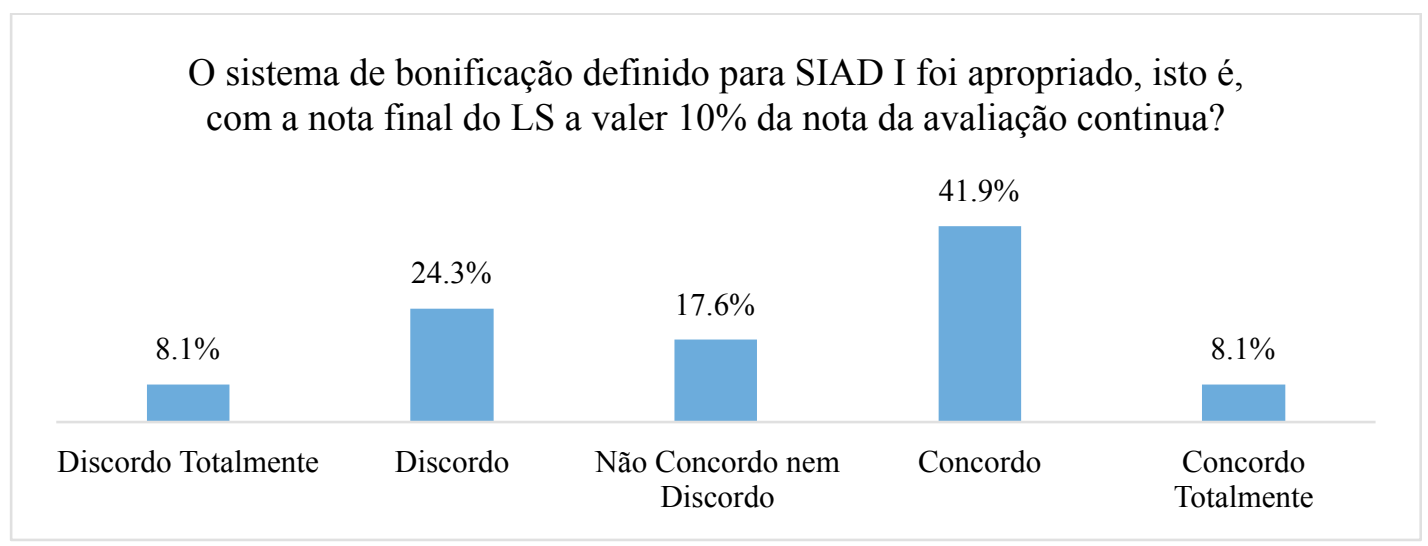

Figura 5 - Satisfação dos alunos face ao sistema bonificado no LS versão 3 


\subsection{Avaliação das mecânicas no LS: XPs e tipos de quests}

Referente à aceitação da participação no LS contar com $10 \%$ da nota da avaliação contínua obteve grande discrepância de opiniões como é demonstrado pela Figura 5. Metade dos jogadores concorda e sente justo o valor dado pela sua participação na plataforma. Afirmando ainda que “integrar o 'jogo' na nota é outro fator de incentivo aos alunos a usar a plataforma apesar de não ser o principal. Apesar de não ter um peso considerável, é suficiente" ou que "permitiu implementar o LS e motivar os alunos a participar, sem um impacto muito elevado que pusesse em causa o efeito de diversão da gamificação”. Foram feitos alguns comentários no questionário e alguns refletem o que inicialmente planeamos como o de que "ao fazer parte da nota, ainda que sejam apenas $10 \%$, é uma motivação extra a que os alunos participem das diversas atividades propostas e muitas vezes, sem que se apercebam, saem beneficiados. Por exemplo, os Quizzes ajudam o aluno a perceber os seus pontos fracos e o que têm de estudar para os superar. Os exercícios ajudam a estudar para que no estudo para a frequência, o aluno não tenha de se estar a relembrar de tudo desde início uma vez que foi praticando".

Os restantes alunos que não concordaram com o valor dividem-se no motivo uns sentem que os $10 \%$ não refletem o tempo despendido e/ou o esforço realizado. Outros sentem que não deveria contar para a nota e funcionar como bonificação na nota.

Relativamente aos mecanismos utilizados na plataforma foram entendidos como suficientes (69\%), ainda assim $21 \%$ das respostas considerou como excessivas como é ilustrado na Figura 6.

Os elementos de gamificação (Leaderboard, Rank, XPs, Quests, Avatar, Badges, Trophies, Last Chance) utilizados na plataforma LS foram:

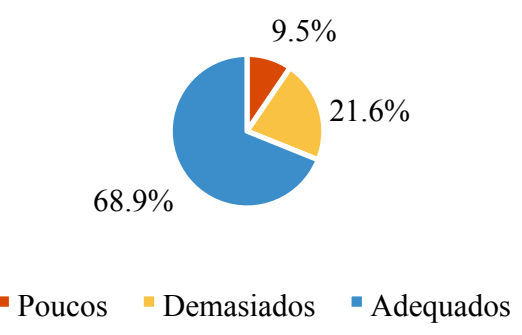

Figura 6 - Opinião dos alunos face ao número de elementos presentes no LS versão 3

As Quests disponibilizadas foram bem-recebidas pelos alunos com exceção do Fórum. Quando analisados os dados obtidos pela plataforma LS foi possível verificar que os alunos realizaram em média 73\% das Quests disponibilizadas, onde as Quests do tipo Practical Assignment foi a que apresentou maior percentagem de realização cerca de $96 \%$ (isto porque é uma quest obrigatória para avaliação contínua). As restantes Quests obtiveram os seguintes valores de realização a Class Attendance $76 \%$, os Quizzes $88 \%$, os Exercises $48 \%$ e o Forum 37\%. Pelos valores apresentados verifica-se que a participação no fórum e nos exercícios foi feita por poucos estudantes, mas este 
tema será detalhado mais à frente. Também procuramos confrontar os alunos sobre a sua principal motivação (pela nota ou pelo jogo) para a realização dos diferentes tipos de Quests e mais de 77\% afirmou ser pela nota. Ainda nesta pergunta nenhum dos alunos referiu ser pelo jogo.

Todavia pela Figura 7 é visível que os XPs atribuídos não foram consensuais, muitos acharam a distribuição de XPs justa, outros sentiram que os pontos ganhos não representavam o esforço realizado.

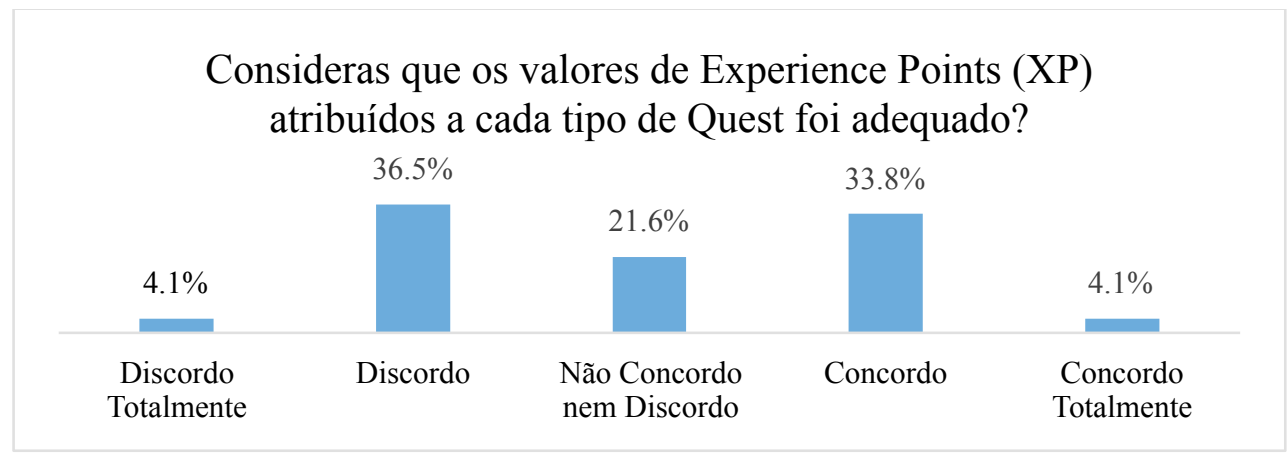

Figura 7- Opinião dos alunos pela distribuição de XPs por cada tipo quest no LS versão 3

\subsection{Avaliação do Fórum}

A quest do tipo Fórum foi a mais controversa; inúmeras respostas iam de encontro de que o fórum não devia ser avaliado. Muitos demostraram o seu desagrado afirmando que as suas dúvidas eram comuns às dos outros colegas e não sentiam a necessidade de expor as suas dificuldades em comentários no Fórum. Um dos comentários que aborda este assunto foi o seguinte "Somos entre 60 a 70 alunos, muitas das dúvidas que surgiram provavelmente são comuns a outros colegas, contudo, apenas um terá a "oportunidade" de a perguntar no fórum sem ser considerado SPAM. O mesmo se passa com quem quer ajudar a esclarecer essas dúvidas. Mesmo que vários colegas saibam a resposta, apenas um terá a oportunidade de a esclarecer no fórum sem ser considerado SPAM".

Neste estudo observou-se que os alunos não exploraram o Fórum da maneira que era pretendido, i.e., com a partilha de outras fontes de informação e com questões que resultassem em discussões. Foram criados inúmeros Badges a expor os objetivos mais valorizados na plataforma LS, mas não foi o suficiente para dinamizar o Fórum. É de salientar que apenas foram atribuídos nove badges do tipo Fórum, a maioria (sete) foram de bronze, que traduz a dificuldade mais baixa dos objetivos propostos. Destes nove badges, um de bronze foi atribuído por ter alcançado os 20 posts pedidos, outros três também de bronze por terem recebido 20 likes nas suas publicações e os restantes três de bronze por terem recebido um pin post num comentário relevante para a turma. Os restantes dois badges foram de ouro por terem encontrado e ajudado na correção de erros no material da UC. Neste último caso, a partilha foi feita diretamente à coordenadora da UC, mas o pretendido 
seria utilizarem o Fórum. No entanto, mesmo assim premiou-se os alunos com a atribuição dos badges.

Apesar destes números, a versão 3 foi a experiência que apresentou melhores resultados em comparação com as versões anteriores do LS, sendo que mais de $74 \%$ achou útil a disponibilização do Fórum no LS para a partilha do conhecimento (ver Figura 8). Alguns comentários dos alunos referem: "concordo plenamente em como o fórum é um ótimo local para expandir os nossos conhecimentos acerca da cadeira" e "porque me permitiu aprender com as dúvidas dos outros e esclarecer dúvidas minhas". Os pontos mais negativos face ao Fórum devem-se essencialmente à demora de respostas às suas questões. O objetivo do Fórum não era ser o professor a responder a todas as questões levantadas, mas sim que existisse uma partilha mais fluida da informação entre os alunos. Esta nova forma de cooperação e colaboração leva a tempo a ser assimilada pelos alunos.

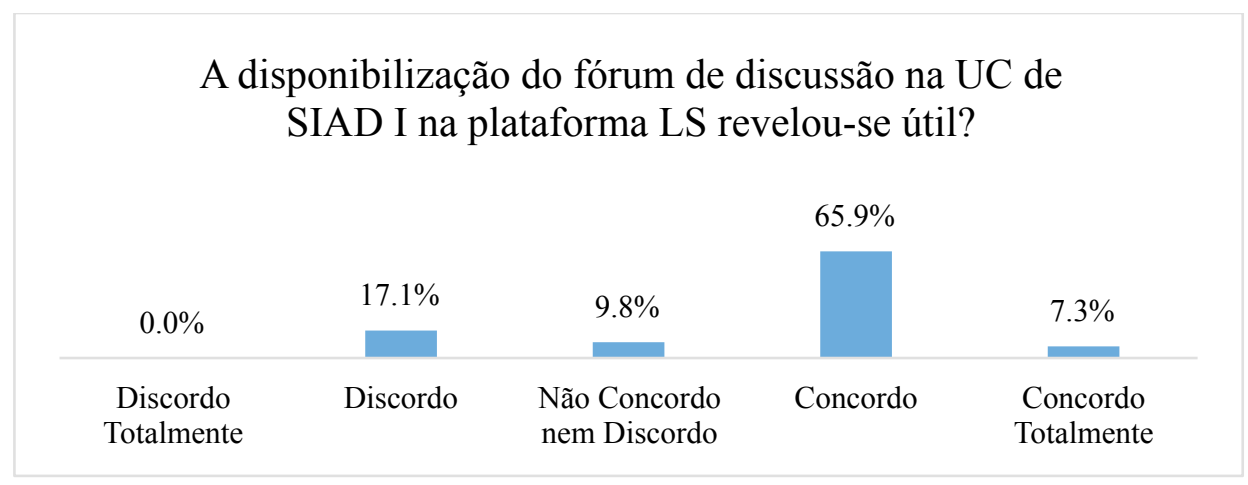

Figura 8 - Opinião dos alunos pela disponibilização do fórum no LS versão 3

\subsection{Avaliação das mecânicas no LS: last chances, badges e trophies}

Como referido anteriormente, determinadas Quests (Quiz, Exercise e Practical Assignment) precisaram de ser validadas para os alunos ganharem XPs. A sua validação consistia em determinar a dificuldade das mesmas. Quando os alunos foram questionados sobre esta regra a grande maioria (mais de 68\%) considerou como apropriada (ver Figura 9). Porém recebeu-se opiniões contrárias, a razão da sua insatisfação deveu-se a terem de realizar e submeter os desafios numa plataforma (e-learning) e terem de os validar no LS; eles queriam a plataforma mais centralizada conforme é dito por alguns alunos: "Acho estranho termos que ir à plataforma avaliar a "quest" depois de a completar noutra plataforma". Esta foi uma opção de desenho na versão 3 e 4, não sendo a ideal foi a exequível, sendo que futuramente passará a ser possível a realização de todas as quests dentro da plataforma LS.

Durante a experiência verificou-se que muitas vezes os alunos realizavam as tarefas, mas não as validavam e acabavam por perder os XPs. A implementação das Last Chances foi assim fundamental, tendo muitos alunos conseguido repescar os XPs que pensaram já terem perdidos 
conforme se pode ver pela Tabela 1. Na versão 3 do LS não foi considerada nenhuma penalização na nota das quests "repescadas".

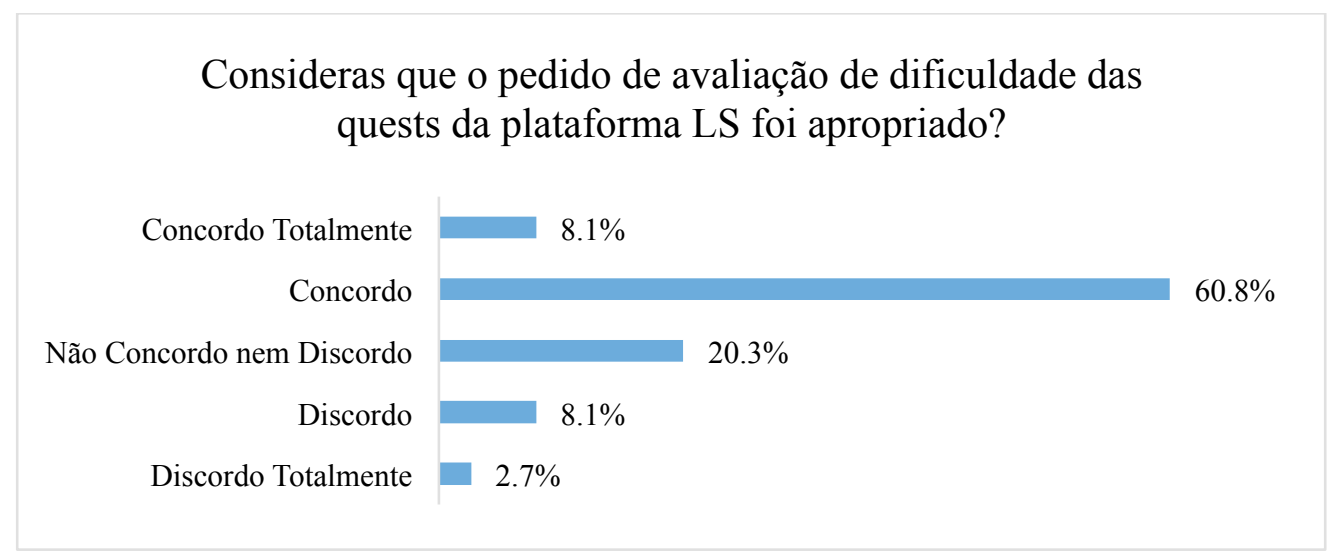

Figura 9 - Opinião dos alunos pela necessidade de avaliação das quests no LS versão 3

\begin{tabular}{|c|c|}
\hline QUESTS & $\mathbf{N}^{\mathbf{0}}$ DE VALIDAÇÕES POR LAST CHANCE \\
\hline Quiz 1 & 4 \\
\hline Quiz 2 & 14 \\
\hline Quiz 3 & 6 \\
\hline Quiz 4 & 2 \\
\hline Quiz 5 & 2 \\
\hline Exercício 1 & 9 \\
\hline Exercício 2 & 11 \\
\hline Exercício 3 & 6 \\
\hline Tutoria 1 & 27 \\
\hline Tutoria 2 & 38 \\
\hline
\end{tabular}

Tabela 1 - Número de Last Chances realizadas por Quest no LS versão 3

Os badges foram um mecanismo que menos adesão teve por parte dos alunos, a média de realizações deste elemento foi de 15\%, um valor bastante baixo. A maioria das críticas baseiam-se na dificuldade de os alcançar. Os badges mais criticados foram os do fórum e os da Guild. Os do fórum deveu-se como já explicado à não compreensão dos alunos do que era valorizado e aos da Guild eles sentiram que não deveriam existir porque estavam dependentes uns dos outros. Neste último a dependência dos restantes membros da Guild serviria para os alunos "puxarem" uns pelos outros.

A partir da Tabela 2 podemos verificar que a categoria individual foi a que obteve um maior número de badges atribuídos. Contudo o seu valor ainda está muito abaixo do desejado. Ainda a partir da Tabela 2 e da Figura 10 é possível compreender facilmente que este mecanismo terá que ser futuramente melhorado ou explorado de forma distinta. Mais uma vez nestes valores está refletido o não cumprimento dos objetivos propostos para o Fórum. O badge do tipo Questionário Final não foi atribuído porque o questionário acabou por ser realizado (excecionalmente) após a atribuição das notas pela participação no LS, já no início do $2^{\circ}$ semestre. 


\begin{tabular}{|c|c|}
\hline CATEGORIAS DOS BADGES & MÉDIA DE BADGES ATRIBUÍDOS (\%) \\
\hline Individual & 43,3 \\
\hline Guild & 26,0 \\
\hline Fórum & 0,3 \\
\hline Questionário Final & 0 \\
\hline
\end{tabular}

Tabela 2 - Média de Badges ganhos pelos alunos por categoria no LS versão 3

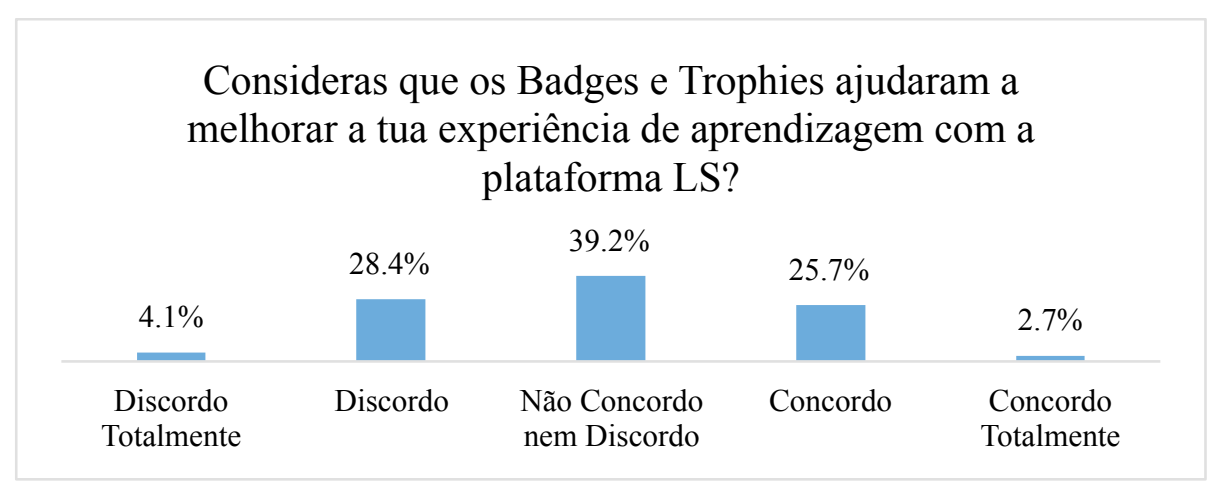

Figura 10 - Opinião dos alunos pela utilização dos mecanismos de Badges e Trophies no LS versão 3

\subsection{Avaliação das mecânicas no LS: leaderboards e ranks}

As Leaderboards e as suas diferentes dimensões são consideradas pelos jogadores, mais de $66 \%$, como uma fonte de motivação. Outro dado que demonstra a sua importância é o número médio de acessos por parte dos alunos às páginas na plataforma dedicadas às Leaderboards que foram em média cerca de 52 acessos por aluno em 15 semanas.

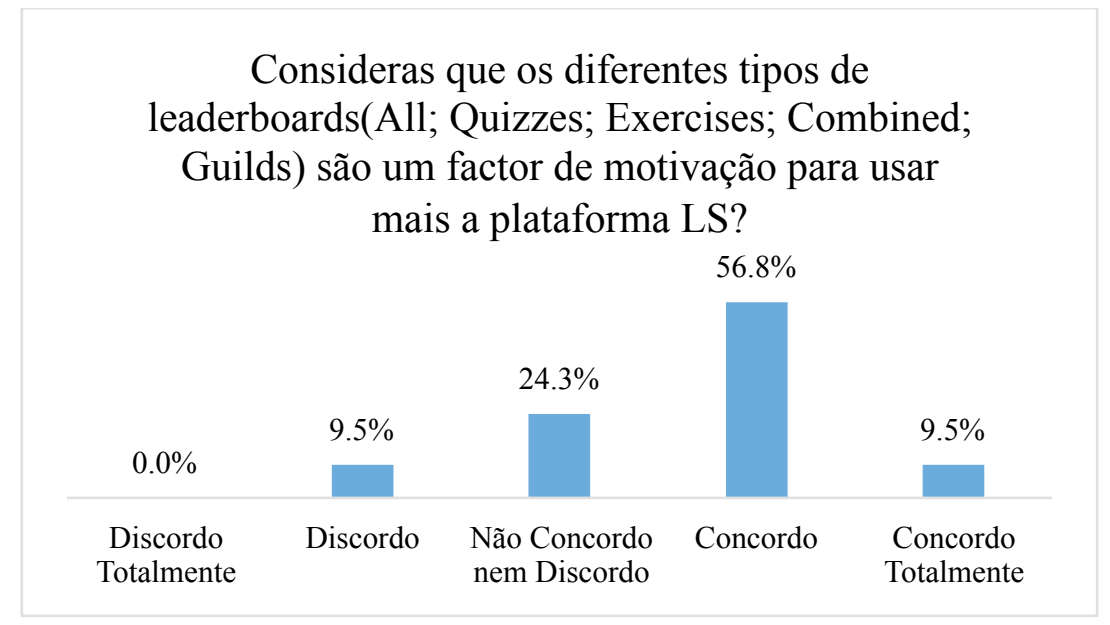

Figura 11 - Opinião dos alunos face ao mecanismo Leaderboard no LS versão 3

$\mathrm{Na}$ Tabela 3 referente à distribuição do número de alunos por cada rank no final da Unidade Curricular verifica-se que a maioria dos alunos se encontram com uma nota igual ou superior a 15 valores na sua participação no LS. Este valor é bastante positivo. Alguns comentários dos alunos referem a acentuada dificuldade em subir de nível, sobretudo nos níveis superiores. Contudo, esta diferenciação das notas pelos ranks foi desenhada de forma propositada no jogo, dado que os 
últimos ranks evidenciam competências de "master" e "legendary" na temática da UC, logo pressupõem um esforço extra para a aquisição de conhecimentos sólidos na matéria lecionada.

\begin{tabular}{|c|c|c|}
\hline RANKS & No ALUNOS POR RANK & NOTA \\
\hline Legendary & 1 & 20 \\
\hline Master & 7 & 18 \\
\hline Expert & 70 & 15 \\
\hline Skilled & 35 & 12 \\
\hline Rookie & 6 & 10 \\
\hline Newbie & 4 & 0 \\
\hline
\end{tabular}

Tabela 3 - Distribuição do número de alunos por cada rank no LS versão 3

\subsection{Avaliação global da utilização do LS}

Por fim quando os alunos são questionados sobre se gostariam de utilizar a plataforma em outra UC, $69 \%$ respondeu que gostaria e a probabilidade de a usarem caso seja aplicada em outra UC sobe para mais de $74 \%$. Os valores demostram um impacto bastante positivo na motivação e/ou comprometimento dos alunos devido à plataforma gamificada. Este impacto também é expresso a partir dos valores apresentados na Figura 12, onde é demonstrado o agrado por mais de $70 \%$ dos alunos com a utilização de uma plataforma académica com elementos de gamificação. A complementar estes dados uma parte significativa dos alunos ainda consideraram a plataforma como uma fonte motivacional para o seu estudo (Figura 13) e que permitiu conseguirem obter uma melhor nota na Unidade Curricular (Figura 14).

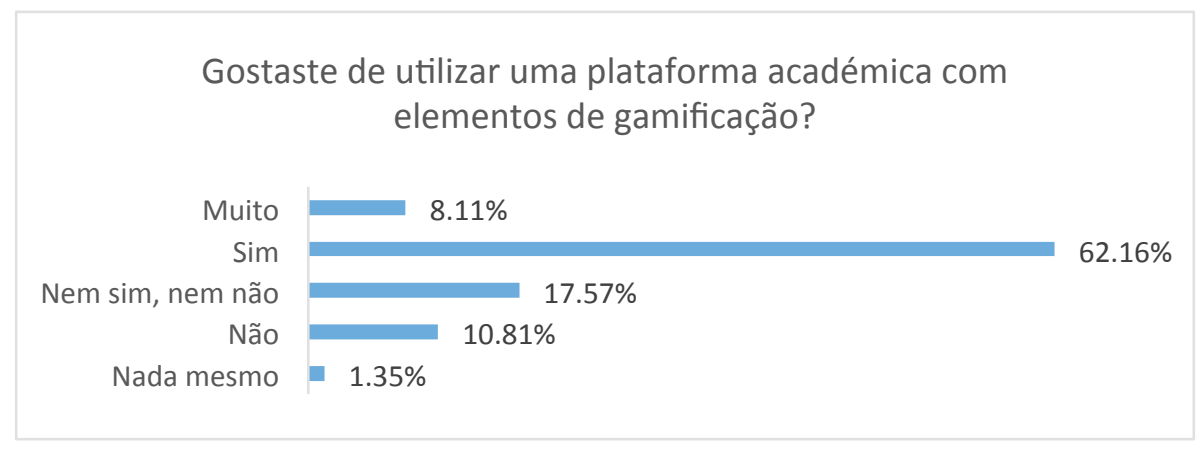

Figura 12 - Opinião dos alunos face ao uso da plataforma com elementos de gamificação no LS versão 3

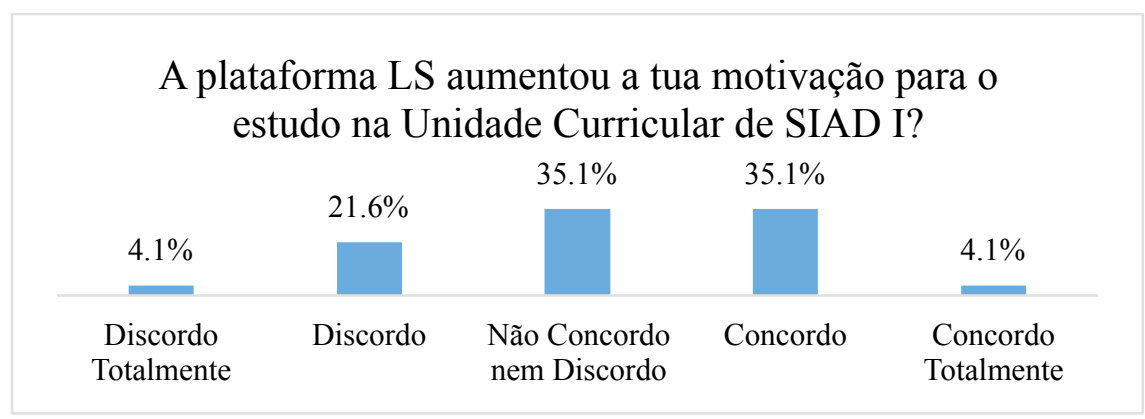

Figura 13 - Opinião dos alunos sobre a motivação produzida pelo LS versão 3 


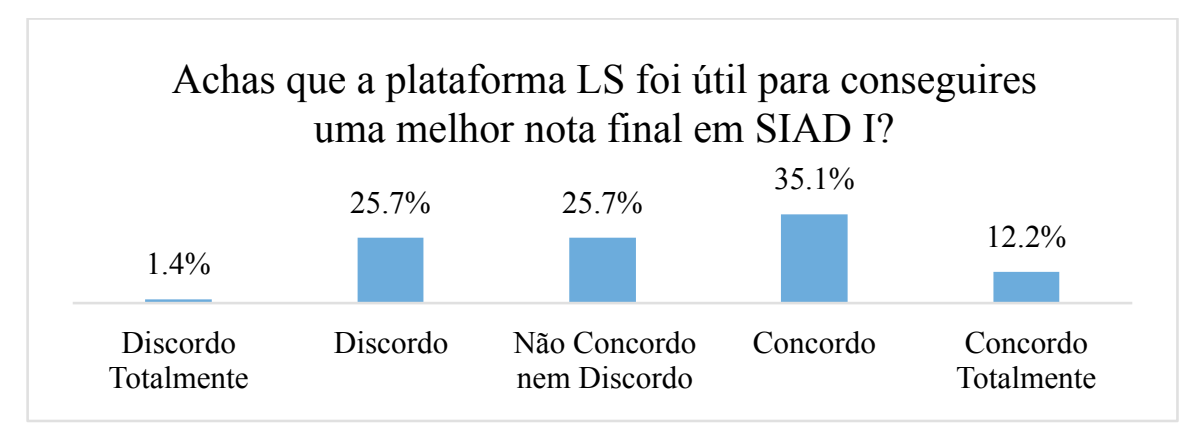

Figura 14 - Opinião dos alunos sobre o impacto na nota pelo uso do LS versão 3

\section{ConClusão}

Neste trabalho foi possível compreender os passos que são necessários para a construção de sistemas com gamificação, com base no desenvolvimento do game design e a taxonomia desses elementos usando a framework MDA. Neste artigo descreveu-se o desenho das mecânicas e dinâmicas de um sistema com gamificação, no âmbito do Learning Scorecard, uma plataforma de Learning Analytics desenvolvida num contexto universitário, cujo foco é melhorar o compromisso e motivação dos alunos para melhorar a sua experiência de aprendizagem numa UC. Estando a plataforma LS atualmente a ser utilizada, neste artigo foi apresentada uma análise do impacto da utilização desta plataforma numa UC do $1^{\circ}$ semestre de 2017-2018 no ISCTE-IUL.

A avaliação da utilização da plataforma e das mecânicas e dinâmicas introduzidas no game design é bastante positiva e encorajadora da continuação da investigação em torno do aperfeiçoamento das técnicas de gamificação do Learning Scorecard.

As principais dificuldades encontradas no estudo foram a não perceção dos objetivos propostos para o Fórum como a partilha de conteúdo relevante e a necessidade de um feedback aos alunos mais célere. Apesar da versão 3 do LS ter sido uma experiência com bastante maior utilização do fórum face às versões anteriores, ainda há amplo espaço para melhorar, sendo fundamental aumentar a motivação dos alunos para a partilha e colaboração através dos recursos existentes no fórum. O feedback constante foi outro dos problemas encontrados nesta experiência. A grande quantidade de alunos e de tarefas disponíveis para os alunos completarem com a necessidade de serem avaliados requer um esforço enorme por parte dos docentes para conseguir com brevidade dar feedback aos alunos.

Nos sistemas onde são aplicadas técnicas de gamificação é preciso ter a noção de que o sistema deve evoluir continuamente. Assim a plataforma LS terá que procurar melhorar o game design com recurso aos dados históricos recolhidos. A mecânica dos Badges deve de ser mais explorada, pois atualmente os alunos ainda não estão a aderir a esta mecânica. Um dos pontos mais importantes a melhorar no futuro e, pedido também pelos alunos, é a centralização na plataforma LS da realização de todas as quests, melhorando sobretudo a integração com o sistema de $e$ - 
learning. Isto porque a integração com o sistema académico da universidade, para o registo de assiduidade já se encontra resolvido.

\section{REFERÊNCIAS}

Cardoso, E., Santos, D., Costa, D., Caçador, F., Antunes, A., \& Ramos, R. (2016, November). Learning scorecard: monitor and foster student learning through gamification. In Proceedings of $2^{\text {nd }}$ International Workshop on Educational Knowledge Management (EKM 2016), Bologna, Italy. Best paper award.

Cardoso, E., Costa, D., \& Santos, D. (2017, June). Introducing the Learning Scorecard: a tool to improve the student learning experience. In Proceedings of $23^{\text {rd }}$ International Conference on European University Information Systems (EUNIS 2017), Münster, Germany. EUNIS Doerup E-learning Award 2017.

Deterding, S., Dixon, D., Khaled, R., \& Nacke, L. (2011, September). From Game Design Elements to Gamefulness: defining "gamification". In Proceedings of the $15^{\text {th }}$ International Academic MindTrek Conference on Envisioning Future Media Environments (MindTrek'11), Tampere, Finland.

Dicheva, D., Dichev, C., Agre, G., \& Angelova, G. (2015). Gamification in Education: A Systematic Mapping Study. Journal of Educational Technology \& Society, 18 (3), 75-88.

Furdu, I., Tomozei, C., \& Köse, U. (2017). Pros and Cons Gamification and Gaming in Classroom. BRAIN. Broad Research In Artificial Intelligence And Neuroscience, 8(2), pp. 56-62. Retrieved from http://www.edusoft.ro/brain/index.php/brain/article/view/689

Hanus, M.D., \& Fox, J. (2015). Assessing the effects of gamification in the classroom: A longitudinal study on intrinsic motivation, social comparison, satisfaction, effort, and academic performance. Computers \& Education, 80, 152-161. https://doi.org/10.1016/J.COMPEDU.2014.08.019

Hunicke, R., LeBlanc, M., \& Zubek, R. (2004). MDA: A Formal Approach to Game Design and Game Research. Workshop on Challenges in Game AI, 1-4. https://doi.org/10.1.1.79.4561.

Lee, J.J., \& Hammer, J. (2011). Gamification in Education: What, How, Why Bother? Academic Exchange Quarterly, 15 (2).

Monterrat, B., Lavoué, E., \& George, S. (2017). Adaptation of Gaming Features for Motivating Learners. Simulation and Gaming, 48 (5), 625-56. https://doi.org/10.1177/1046878117712632.

Németh, T. (2015). The Definitions of Gamification, http://ludus.hu/en/gamification/ (6 Maio 2018)

Prensky, M. (2001). Digital Natives, Digital Immigrants. From On the Horizon, MCB University Press, 9 (5).

Regina, C., Losso, C., \& Borges, M.C. (2015). Gamificação em Pesquisas em Educação: uma Revisão da Produção Acadêmica." $2^{\circ}$ Colóquio de Educação com Tecnologias - Aprendizagem Aberta e Invertida, 1-21.

Sánchez-Mena, A., \& Martí-Parreño, J. (2017). Drivers and Barriers to Adopting Gamification: Teachers' Perspectives. Electronic Journal of e-Learning, 15 (5), 434-443.

Werbach, K., \& Hunter, D. (2012). For the Win: How Game Thinking Can Revolutionize Your Business. Wharton Digital Press. https://doi.org/10.1017/CBO9781107415324.004.

Zichermann, G., \& Cunningham, C. (2011). Gamification by Design: Implementing Game Mechanics in Web and Mobile Apps ( $1^{\text {st }}$ edition). O'Reilly Media. 